\title{
O coletivo como floresta e a pedagogia da imanência
}

\author{
The Collective as Forest \\ and the Pedagogy of Immanence \\ El colectivo como bosque \\ y la pedagogía de la inmanencia
}

Rafael Zacca Fernandes *

http://dx.doi.org/10.22409/poiesis.2033.55-74

\begin{abstract}
RESUMO: O presente artigo explora a possibilidade de uma comunidade transespecífica, definida mais pela categoria de convivência do que pela do comum. Para isso, explora a genealogia do conceito de cultura tal como constituído historicamente até as suas acepções modernas. Depois, o artigo demonstra a possibilidade de engendramento de outro conceito de cultura no Brasil, pressentido por nossa poesia, em sua vocação para uma incomunidade. À semeIhança do conceito de floresta, a cultura aparece como um meio ambiente em que convivem as transepecificidades. Por fim, explora a afinidade desta vocação com a de uma existência pedagógica em nossa cultura, principalmente com a filosofia de Paulo Freire. Traz ainda uma constatação final, a saber: a de que as formas da colaboração nos coletivos de arte contemporâneos traduzem uma vocação de um outro povo, sonhado por Oswald de Andrade como aquele que não dicotomiza a escola (o saber) e a floresta (o meio).
\end{abstract}

PALAVRAS-CHAVE: coletivo; cultura; pedagogia; transespecificidade

\footnotetext{
"Rafael Zacca Fernandes é doutor em Filosofia (PUC-Rio) e professor substituto de Teoria Literária do Departamento de Ciência da Literatura da UFRJ. E-mail: zacca.rafael@gmail.com
} 
ABSTRACT: This paper explores the possibility of a transpecific community, defined more by the category of living together than by that of communality. In order to achieve this, the text explores the genealogy of the concept of culture as historically constituted up to its modern understanding. Afterwards, the possibility of engendering another concept of culture in Brazil is demonstrated, sensed by our poetry in its propensity for an incommunity. Similar to the concept of the forest, culture appears as an environment (a medium) in which transpecificities coexist. Finally, it explores the affinity of this propensity with that of a pedagogical existence in our culture, especially within the philosophy of Paulo Freire. It also presents a final observation: that the forms of collaboration in contemporary art collectives reflect a vocation of a different people, dreamed by Oswald de Andrade as one who does not dichotomize the school (the knowledge) and the forest (the medium).

KEYWORDS: collective; culture; pedagogy; transpecificity

RESUMEN: El presente artículo indaga la posibilidad de una comunidad transespecífica, definida más por la categoría de convivencia que por la de lo común. Para esto, explora la genealogía del concepto de cultura tal como se ha construido históricamente hacia sus acepciones modernas. Después, el artículo presenta la posibilidad de engendramiento de otro concepto de cultura en Brasil, presentido por nuestra poesía, en su vocación para una "incomunidad". A semejanza del concepto de bosque, la cultura aparece como un medio ambiente en el que conviven las transespecificidades. Por último, reflexiona sobre la afinidad de esta vocación con la de una existencia pedagógica en nuestra cultura, especialmente con la filosofía de Paulo Freire. El texto aporta también una constatación final: la de que las formas de colaboración en los colectivos de arte contemporáneo traducen una vocación de un otro pueblo, soñado por Oswald de Andrade como aquel que no dicotomiza la escuela (el saber) y el bosque (el medio).

PALABRAS CLAVE: colectivo; cultura; pedagogía; transespecificidade

Como citar: FERNANDES, Rafael Zacca. O coletivo como floresta e a pedagogia da imanência. Poiésis, Niterói, v. 20, n. 33, p. 55-74, jan./jun. 2019. doi: http://dx.doi.org/10.22409/poiesis.2033.55-74

Poiésis, Niterói, v. 20, n. 33, jan./jun. 2019. 


\section{0 coletivo como floresta e a pedagogia da imanência}

No século XX, a forma do coletivo na produção da arte foi uma exceção. Reservava-se às vanguardas (artísticas e políticas), aos limites práticos de alguns movimentos sociais, ou mesmo ao mercado e à indústria, como no caso do cinema. No entanto, neste último caso, o esquema da divisão do trabalho, segundo as categorias empregadas na produção, dificilmente permite classificá-la como coletiva. O modo de produção da arte na modernidade (desde o desaparecimento progressivo das guildas e das cooperativas medievais) conheceu como regra a produção e a assinatura individuais. Uma estranha tendência, no entanto, reemerge no século XXI. A coletividade se coloca, se não numericamente hegemônica, pelo menos estruturalmente incontornável. No Brasil, esta tendência se funda ainda sobre outra: uma forte vocação para uma pedagogia da imanência. Desde esse ponto de vista, o coletivo, no Brasil, tende para relações de aprendizagem coladas às relações de produção. Para compreendê-lo, será instrutivo perceber como a dicotomia burguesa entre o indivíduo e o coletivo se funda em certa compreensão do par natureza/cultura tanto no centro da modernidade quanto em sua periferia. ${ }^{1}$ 


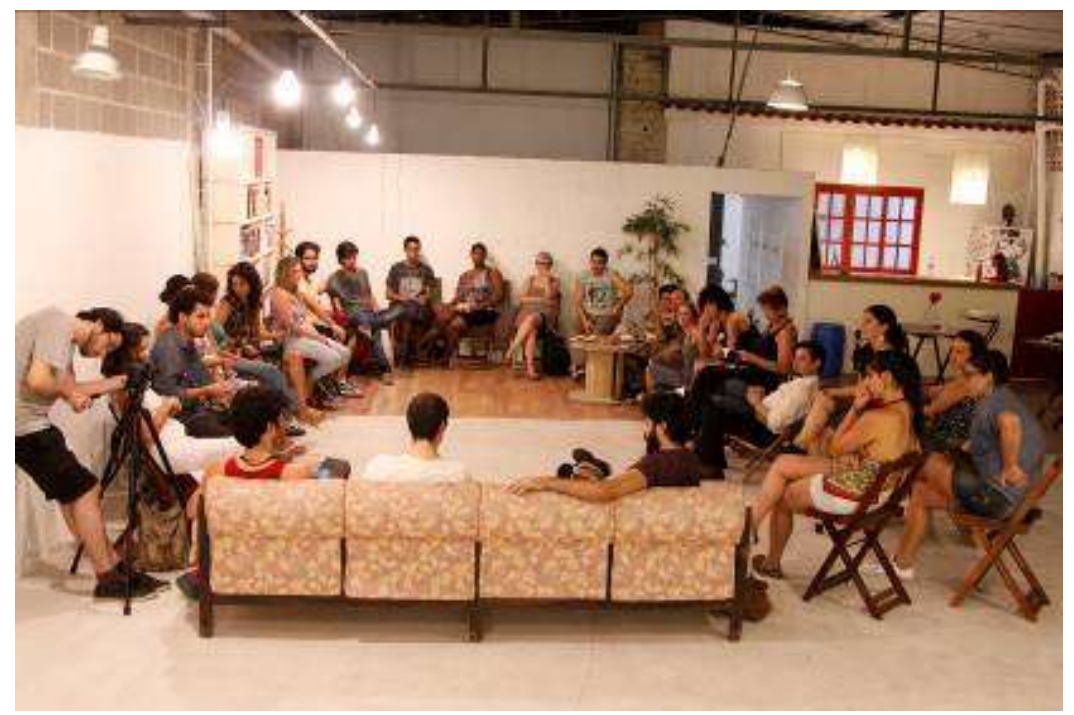

Fig. 1 - O coletivo Oficina Experimental de Poesia no galpão do coletivo És uma maluca em 2015. (Fonte: Acervo do coletivo Oficina Experimental de Poesia)

Poiésis, Niterói, v. 20, n. 33, jan./jun. 2019. 


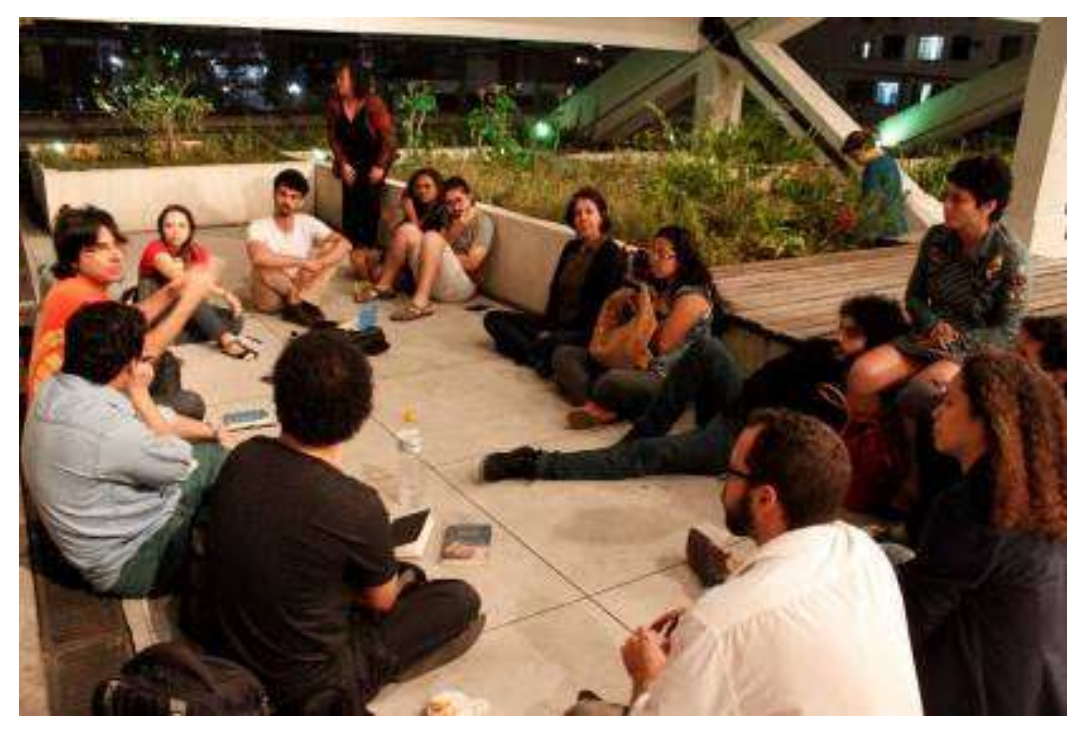

Fig. 2 - O coletivo Oficina Experimental de Poesia recebe Alberto Pucheu no terraço do Imperator em 2014. (Fonte: Acervo do coletivo Oficina Experimental de Poesia) 
A separação entre natureza e cultura é, ela mesma, um dado cultural do ocidente, que denuncia a sua própria natureza. Há milênios ela é preparada, principalmente com a revolução da agricultura, com o sedentarismo e com a divisão do trabalho (ELIADE, 2010, pp. 41-65), mas foi a modernidade capitalista que se mostrou capaz de dar o golpe que separaria os dois conceitos como duas montanhas que veem, entre elas, um abismo intransponível. A separação já se encontra naquela divisão grega entre bíos e zoé, que tinge a vida humana com as tintas da política, de um lado, e da animalidade por outro. (ARENDT, 2014, pp. 27-98; 2013, pp. 69-65)

Foi com a emergência da burguesia, porém, que o conceito de cultura recebeu a sua face fetichizada. Graças, é claro, à mercantilização da vida e das relações sociais, que consolidou a transformação do conceito. Se, em sua raiz latina, ele carrega o significado de cultivo (ainda empregamos esse sentido quando falamos em cultura da soja, cultura do arroz etc.) (CHAUÍ, 2018, pp. 15-28), no uso contemporâneo ele tende a se referir a dois sentidos que se destacam da ideia de natureza. Eles acompanham os sentidos da forma mercadoria: em primeiro lugar, como reificação, ou coisificação; em segundo lugar, como charme.

Por um lado, cultura se tornou sinônimo de tesouro (coisas) de um povo: bens culturais acumulados historicamente, dispostos em museus, registrados em livros e expostos em centros culturais. Poderíamos identificar essa como uma forma bancária da cultura²: ela é o capital pelo qual uma cultura se define, e pelo qual essa mesma cultura pode ser identificada como dominante (se o seu capital é valorizado) ou dominada (no caso de cofres esvaziados, por meio de uma relação de dependência cultural). Por outro lado, cultura também se tornou sinônimo de modo de vida complexo (charme) e distante de uma "vida natural" (real ou suposta) que fosse capaz de nos igualar a todos. Desse ponto de vista, a cultura é o modo pelo qual cada povo foi capaz de superar problemas e condicionamentos originais, fazendo com que o ser humano se distanciasse assim de sua autenticidade como espécie e se aproximasse, em bandos, em grupos, a diferentes modos de ocupação e reprodução da vida social.

Poiésis, Niterói, v. 20, n. 33, jan./jun. 2019. 
A "natureza" - identificada com a flora e a fauna e destacada da vida humana - exerce assim um papel de outro fascinante no ocidente. Feitiço do qual não escapam os poetas pelo contrário, confirma-se em sua pena. Se eles são uma espécie de "antena da raça", como afirmou certa vez Ezra Pound (1976, p. 77), é instrutivo perceber que Dante faz a sua peregrinação ao Paraíso depois de ser resgatado da selva-selvagem por Virgílio (ALIGHIERI, 2010, p. 25), e que Baudelaire mede os perigos da grande cidade em comparação com os da floresta, identificando a brutalidade urbana como uma segunda natureza (BAUDELAIRE, 1995, p. 289), que Marinetti exaltou a beleza da guerra comparando o aparato bélico a uma flora exuberante. (MARINETTI apud BENJAMIN, 2017, p. 46)

Outra é a sensibilidade da "raça" dos trópicos que as antenas daqueles que escrevem aqui captam. Nos manifestos de Oswald de Andrade, por exemplo, cultura é natureza e natureza é cultura. Por isso não entram em par contrastante, opositor ou complementar. São a mesma coisa. Por isso, o seu conceito de barbárie não se opõe ao de civilização: isso possibilita, no Manifesto Antropófago, o reclame por um "bárbaro tecnizado"3 (ANDRADE, 2011, p. 69), décadas antes da distopia científica do cinema hollywoodiano. Essa barbárie também comparece no Manifesto Pau-Brasil: "Bárbaros, crédulos, pitorescos e meigos. Leitores de jornais. Pau-Brasil. A floresta e a escola. O Museu Nacional. A cozinha, o minério e a dança. A vegetação. Pau-Brasil". (ANDRADE, 2011, p. 66)

Esse entendimento que desafia a tradição ocidental se sustenta em nossa poesia até os dias de hoje. Nesse sentido, duas poetas da nova geração de escritoras no Brasil, e seus dois primeiros livros, talvez funcionem como "antena da raça". Mugido, de Marília Floôr Kosby, por exemplo, produz relações de parentesco interespecíficas. A poeta escreve poemas em que há mais parentesco das mulheres com as vacas do que com os homens. Seus versos convivem (e nos fazem conviver) com a vaca, pelo menos com a vaca poetificada no mugido, pela força da proliferação de " $m$ "s, como propõe o poema que abre o Mugido, chamado, justamente, "mmmmmm", em que podemos ler que "o mugido foi a ação escolhida" para uma "desarticulação". Kosby propõe que essa desarticulação se efetua a partir de "um êxodo / de uma tal condição / humana". (KOSBY, 2017, p. 11) 
Esse êxodo não nos deve remeter a uma fuga, mas a um nomadismo. Examinemos meIhor a questão. No prólogo de $A$ condição humana, Hannah Arendt tece algumas considerações a respeito da "fuga da Terra" mobilizada pelo lançamento do Sputnik 1, em outubro de 1957, pela URSS, que orbitou em torno do planeta por 3 meses, enviando um pequeno sinal de rádio que poderia ser captado inclusive por rádios amadores. O lançamento foi realizado com o auxílio de um foguete R-7 Semyroka e significou um teste dos limites que encarceravam o ser humano na Terra, reforçando a tomada de posição do humano como habitante não mais do seu planeta, mas do universo. O mesmo foguete R-7, que serviria ainda como arma de combate e aniquilamento, serviu para que o ser humano sondasse chances de fuga de seu primeiro habitat. Esse evento sinaliza, para Hannah Arendt, um verdadeiro niilismo contemporâneo: uma vontade de fuga da condição terrestre, da vida "como nos foi dada", compreendida pelo ser humano como prisão. "A reação imediata", diz o prólogo de $A$ Condição humana, a propósito do modo como foi noticiado o lançamento do Sputnik 1, "expressa no calor da hora, foi alívio ante o primeiro 'passo para a fuga dos homens de sua prisão na Terra'". (ARENDT, 2014, p. 1)

Se o avanço da tecnologia (e, contemporaneamente, do capitalismo) é identificado como chance de fuga da Terra (e, portanto, de colonização, domínio e assentamento em outros planetas e corpos celestes), é fácil perceber porque, historicamente, alguns movimentos políticos, artísticos e filosóficos quiseram se contrapor a esse destino das forças produtivas a partir da imagem idílica de um retorno à terra como paraíso natural a ser reconquistado. Desde a Lebensphilosophie até certas vertentes do romantismo, o antídoto contra o veneno da fuga foi a refamiliarização com a vida natural, com a Terra, com a natureza etc. Uma fuga, portanto, para o interior (tanto o geográfico, longe dos litorais e da atmosfera, quanto o psíquico). Duas saídas civilizacionais. Mas é contra as duas fugas da civilização, a que escapa para "fora" e a que escapa para "dentro", que Kosby nos oferece a imagem de um êxodo bárbaro.

O que significa esse êxodo? A palavra deriva do grego éksodos, que significa "passagem", "saída" (ou, literalmente, um "fora", ex, do caminho, ódos). Contemporaneamente, remete ao deslocamento de grupos inteiros de pessoas de uma região para a outra, implican-

Poiésis, Niterói, v. 20, n. 33, jan./jun. 2019. 
do, portanto, um estranhamento, uma condição de estrangeiridade. O estrangeiro suporta tanto a diferença da língua quanto a diferença de direitos desde pelo menos a Grécia Antiga - aliás, justamente na Tragédia Grega, segundo Aristóteles, chamamos éksodos o momento em que o Coro anuncia, sem canto, o desfecho da peça. (ARISTÓTELES, 2017, p. 111) No Mugido, esse êxodo implica, simultaneamente, a condição estrangeira do animal e da mulher, promovendo, por exemplo, uma identidade maior entre as "fêmeas" de todas as espécies do que entre a "fêmea" e o "macho" humanos. Implica também o sonho do fim da "peça teatral" do doméstico: "todos aqueles cães / eram cadelas // bocetas ao sol / não é todo dia". Reforça este encontro de significados o comentário de Angélica Freitas, em forma de poema ("muuuu") ao final do livro: "Ler poemas como quem presta atenção, de verdade, em uma fêmea de outra espécie. / Para se entender". (KOSBY, 2017, p. 107)

A empatia interespecífica, entre espécies, também habita a poesia de $A$ primavera das pragas, de Ana Carolina Assis. Em seus versos, porém, a consequência coletiva dessa empatia leva a lugares insuspeitos. A subjetividade se identifica e aprende com outras espécies, inclusive as microscópicas. A começar pelo título do livro, que sugere uma confusão produtiva entre a germinação, a revolta política e as comunidades de insetos e micro-organismos. Refere-se, é claro, à Primavera de Praga; como também, por extensão, à Primavera Árabe e à mais distante Primavera dos Povos, do século XIX. Trata-se de um conjunto intertextual de revoltas contemporâneas e modernas. Em segundo lugar, refere-se também às pequenas comunidades que destroem antigos arranjos. E, por isso mesmo, uma "primavera" de "pragas", um florescer das feridas, une pares que costumamos acreditar como opositivos. Isto é, macropolítica e micropolítica não se opõem, significam a mesma coisa; o mesmo se pode dizer de bioma e política; idem para florescimento e desenvolvimento social. A escola e a floresta de Oswald ganham aqui novos desdobramentos.

Adelaide Ivánova acreditou ver nessa poesia uma "revolução dos bichinhos". (IVÁNOVA in ASSIS, 2019, pp. 67-69) Não à toa vemos siris, caranguejos, fungos, lesmas e outros bichos pequenos se misturando à vida prática e sentimental humana. Vejamos, por exemplo, um poema como "praga", de onde surge o título do livro de Assis:

Poiésis, Niterói, v. 20, n. 33, jan./jun. 2019. 


\author{
apago pego no sono \\ ao lado de desconhecidos \\ sinto fungos a acidez nas coxas \\ a mari disse cravo óleo de coco \\ e bicarbonato de sódio curam \\ a palavra cândida também \\ significa aguardente de cana \\ cachaça fungos \\ que podiam tornar o vinho \\ em vinho mas \\ seguem aqui ardendo \\ quando dão trégua \\ apago pego no sono \\ ao lado de desconhecidos \\ a palavra cândida também \\ pode ser um nome como a \\ cândida erêndida que torcia \\ a roupa de cama branca em \\ que sua vó a vendia pros homens \\ a palavra cândida também significa \\ branca \\ e lembrei do arroz que \\ catei com a vó as \\ mariposas puseram ovos \\ nos sete quilos de arroz \\ da casa dos ovos \\ saíram bichinhos a vó \\ disse está limpo mas \\ preciso que você também \\ cate catamos \\ tivesse dinheiro não tinha \\ escolha ela dizia \\ apago pego no sono \\ ao lado de desconhecidos \\ enquanto atravesso arroz já
}

Poiésis, Niterói, v. 20, n. 33, jan./jun. 2019. 


\section{cândido cachaça e ponte \\ presidente costa e silva rumo à \\ tua casa que fica agora \\ na rua Venceslau queé \\ como se chama também a praça \\ da primavera de praga}

\section{(ASSIS, 2019, pp. 41-42)}

O estado indiscernível da palavra "cândida", entre significante e pluralidade de significados (uma personagem de Gabriel García Marquez, uma infecção genital causada por um fungo, a pureza de caráter etc.) e da palavra praga, entre textos verbais e históricos (a praga como ferida, como infestação, como evento histórico e, em curto-circuito com ele, fazendo coincidir uma rua do Rio de Janeiro com uma praça da República Tcheca), sugerem um estado indiscernível de uma coletividade formada na diferença. Essa coletividade de diferentes, e não de iguais, inaugura um espaço de colaboração entre aqueles que se reconhecem como incomuns (uma incomunidade) que se abre não aos discursos, mas aos diálogos. Na poesia de Oswald de Andrade, o aprendizado não ocorre sem os indígenas e o porvir do matriarcado; em Marília Floôr Kosby, não ocorre sem as vacas e seu mugido; em Ana Carolina Assis, esse aprendizado só pode ocorrer na incomunidade dos muitos bichinhos.

Há em nossa cultura qualquer tendência à diferença - e isto se manifesta na poesia - ainda que as classes dominantes tentem mitigá-la com força e com ideologia. Nesse sentido, há uma tendência brasileira - e latino-americana - ao entendimento da cultura como uma incomunidade, ou como uma coletividade heterogênea, que partilha e disputa diferentes modos de vida, fazeres, saberes e modulações simbólicas. Há, por assim dizer, uma vocação de um conceito: o de cultura como coletividade heterogênea ou como floresta. 


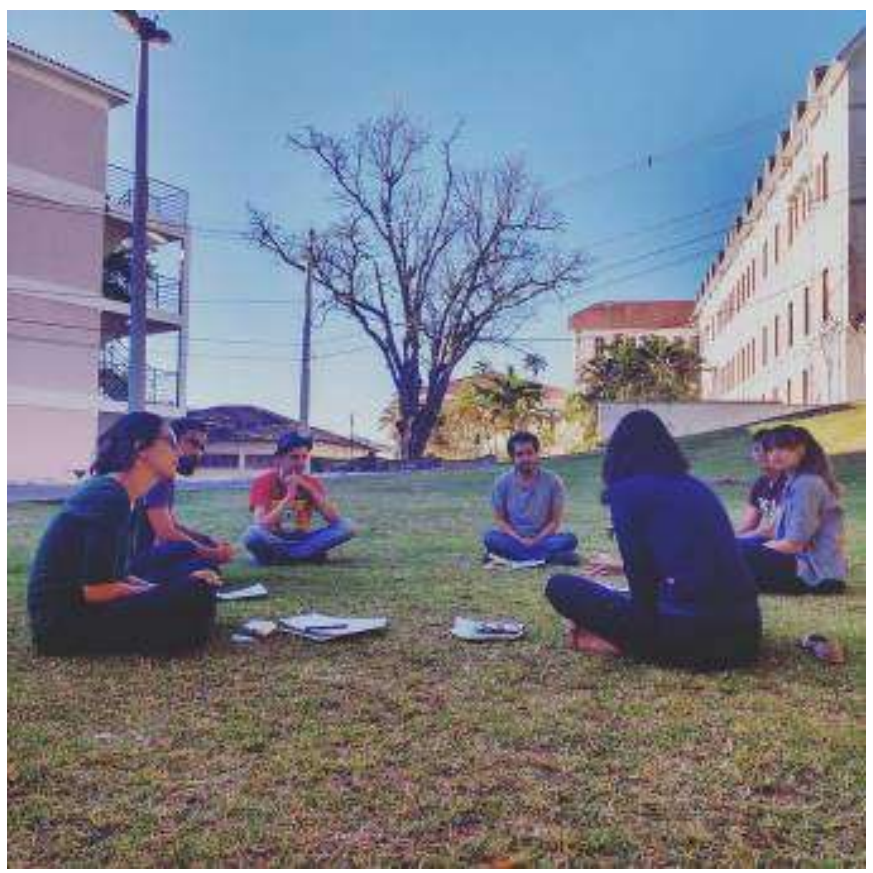

Fig. 3 - Oficina em São João del Rey, Festival de Inverno, 2017.

(Fonte: Acervo do coletivo Oficina Experimental de Poesia)

Poiésis, Niterói, v. 20, n. 33, jan./jun. 2019. 


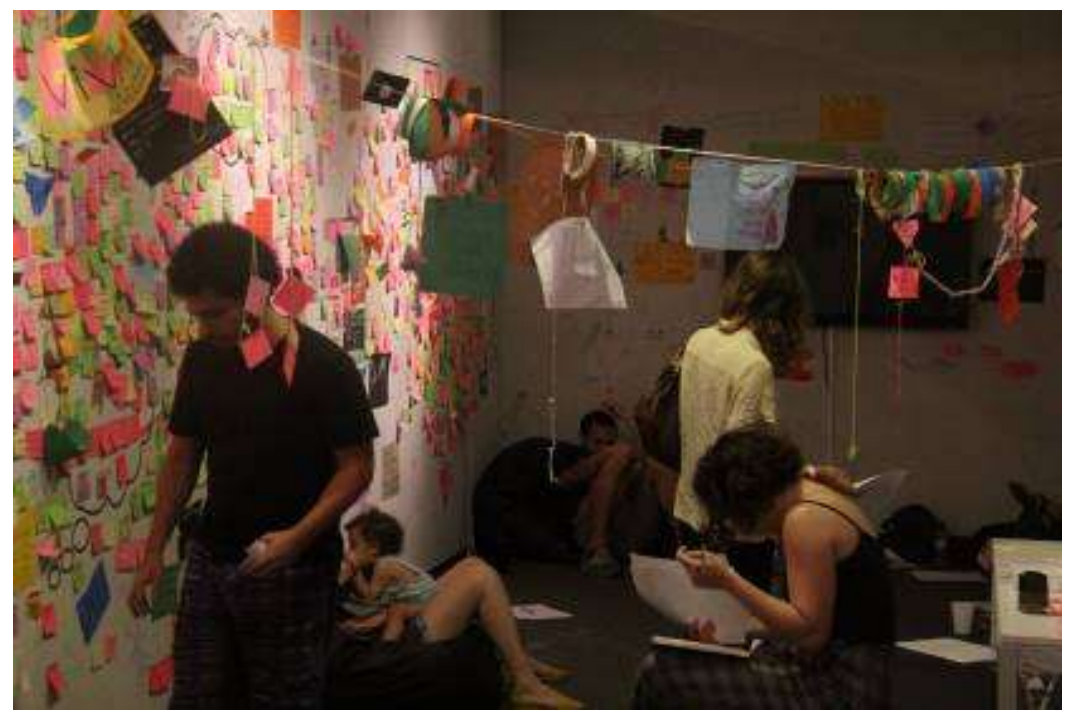

Fig. 4 - Oficina no Museu de Arte Moderna do Rio de Janeiro, por ocasião do Prêmio Pipa 2015. (Fonte: Acervo do coletivo Oficina Experimental de Poesia) 
A floresta é um coletivo de coletivos. Ou um coletivo de povos. Abrange a ideia de fauna e de flora, que são conceitos transespecíficos. Acolhem, portanto, uma diferença fundamental: não classificam seres semelhantes, mas seres que convivem. Os agrupamentos por espécie, ou mesmo por gênero, fundam diferenças e semelhanças a partir de dados ontológicos que aprisionam os seres. A fauna e a flora de um lugar, pelo contrário, não designam dados somente ontológicos, mas também espaço-temporais. $\mathrm{E}$ a própria floresta se livra da classificação ontológica, já que agrupa seres orgânicos e inorgânicos. É o que acontece com nossa vocação para o conceito de cultura - com isso, temos a chance histórica de fundar a cultura como aquilo que se cultiva entre os que convivem. A floresta, portanto, é um coletivo - mas um coletivo dos diferentes. Porque não se coloca como uma força ontológica que constrange os conviventes, mas como meio ambiente em que eles podem habitar. Assim, os critérios culturais deixam de ser ideais (metafísicos) e passam a ser imanentes, pertencem ao meio ambiente em que se encontram.

É isto que está em jogo na animalidade mobilizada por Marília Floor Kosby e Ana Carolina Assis. Também em jogo na poesia de Oswald de Andrade, que antecipou essa coletividade heterogênea. Em "Erro de português", essa vocação se apresenta em uma inversão curiosa:

\section{Quando o português chegou \\ Debaixo de uma bruta chuva \\ Vestiu o índio \\ Quepena! \\ Fosse uma manhã de sol \\ oíndio tinha despido \\ 0 português.}

(ANDRADE, 1974, p. 177)

Poiésis, Niterói, v. 20, n. 33, jan./jun. 2019. 
O título alude a uma ambivalência: o erro é de português como povo e como idioma. 0 que se anuncia é também a chance de um aprendizado. Não por acaso se desenhou entre nós uma pedagogia da imanência, cujo principal impulso foi dado pela filosofia de Paulo Freire. Que a sua filosofia se funde em nossa vocação para a floresta - que a escola e a floresta de Oswald encontrem em sua filosofia a sua face mais fecunda - ainda não foi suficientemente esclarecido. Pois há, na pedagogia e na concepção da humanidade em Freire, não apenas a constatação da existência como também da necessidade da diferença no processo do vir-a-ser de qualquer ser humano.

Na Pedagogia do oprimido, a categoria do inacabado é incontornável. ${ }^{4}$ Mundo e ser humano são definidos pelo signo de seu inacabamento. Porque o mundo precisa ser feito, permanentemente, os seres humanos são os seus coautores; porque o ser humano nunca se estabiliza em uma forma definitiva e acabada, ele é sempre coautor de sua própria existência e da existência dos outros. É nesse sentido que a categoria auxiliar da colaboração pode ser depreendida de uma tal concepção. Isto é, Paulo Freire valoriza a ideia de colaboração não apenas para combater a ideia de competitividade - que domina as formas de trabalho capitalistas, contra as quais Freire se levantou -, mas também porque a própria existência humana e do mundo não seriam concebíveis sem essa ideia. (FREIRE, 2018, p. 226-234)

A vocação pedagógica na cultura brasileira sempre foi pressentida por nossa poesia. A proliferação de oficinas nas últimas décadas atesta isso, desde as promovidas por poetas individualmente, como as de Carlito Azevedo ou Angélica Freitas, até as promovidas por coletivos, como as realizadas pela extinta Oficina Experimental de Poesia e pela iniciativa Mulheres que escrevem. Mas também a própria linguagem poética a testemunha. Sua face mais nítida figura em João Cabral de Melo Neto, conterrâneo e contemporâneo de Paulo Freire. O poeta pernambucano escreve uma poesia em que a relação entre as coisas é pedagógica. Por exemplo em $A$ escola das facas, livro em que figura um poema homônimo que diz: 


\section{0 alísio ao chegar ao Nordeste \\ baixa em coqueirais, canaviais; \\ cursando as folhas laminadas, \\ se afia em peixeiras, punhais. \\ Por isso, sobrevoada a Mata, \\ suas mãos, antes fêmeas, redondas, \\ ganham a fomee 0 dente da faca \\ com que sobrevoa outras zonas. \\ 0 coqueiro e a cana Ihe ensinam, \\ sem pedra-mó, mas faca a faca, \\ como voar o Agreste e o Sertão: \\ mão cortante e desembainhada.}

\section{(MELONETO, 1980, p. 46)}

No poema, a atividade poética e a existência se dão a partir de relações pedagógicas, de ensino-aprendizagem. $O$ que o vento alísio aprende nas folhas laminadas, quer dizer, cursando as folhas laminadas, nesse duplo sentido que tem para nós a palavra e o verbo "cursar", se revela como uma pedagogia entre coisas. Vento, folhas, coqueiral, cana. Mas as coisas estão saturadas de relações humanas: o coqueiro e a cana, que cortam, ensinam o corte ao vento, porque o Agreste e o Sertão aprenderam o modo de existência da "mão cortante e desembainhada". Existe algo que atravessa essa colocação poética e a filosofia de Paulo Freire, desde o primeiríssimo Educação como prática da liberdade: o modo de aparecimento das palavras geradoras no método de alfabetização é análogo ao modo existencial das palavras em João Cabral, com sua pedagogia do dentro para fora.

Se assumirmos que a floresta é um destino de nossa cultura - malogrado pela ação das classes dominantes -, teremos de admitir também que essa floresta exige uma pedagogia. Assim, como em Freire, a pedagogia se apresenta como destruição da violência que se constitui como obstáculo para o ser-mais a que todo ser humano aspira, também a flores-

Poiésis, Niterói, v. 20, n. 33, jan./jun. 2019. 
ta - o coletivo - exige uma forma pedagógica. Porque os seres que se fundaram na cisão entre natureza e cultura não podem, automaticamente, por um suposto saber que possam adquirir, entrar novamente na floresta. Não existe imediatismo que possa transpor a distância abissal que se colocou entre a civilização e a floresta.

Essa pedagogia, no entanto, também não é automática. Não se trata de uma educação para a floresta. Foi Walter Benjamin quem, nos anos 1930, alertou que a pedagogia, a educação, a escola, enfim, não é ela mesma libertadora - um saber que consolidou a dominação não pode ser ele mesmo libertador. (BENJAMIN, 2012, p. 133) Somente um saber "reflorestado", que seja ele mesmo floresta (isto é, que aconteça, ele mesmo, em um meio ambiente análogo à floresta) pode instaurá-la. Isto significa que os coletivos de arte - naqueles em que a forma da colaboração não é fachada, mas que integram todos os participantes em todas as etapas do processo produtivo, dividindo realmente tanto o trabalho quanto os lucros e os ônus materiais e simbólicos - e os coletivos políticos encarnam a chance de realizar uma tarefa inacabada em nossa história. A de um reflorestamento cultural.

Uma pedagogia que não seja ela mesma floresta, desde os seus princípios até a sua finalidade, não pode instaurar uma floresta. A floresta precisa ser um porvir e uma prévia dessa prática. O que isso significa, de fato? Que a chance de uma outra cultura, em nós, depende do acolhimento transespecífico em um meio ambiente (este meio ambiente é a prática dos coletivos, mas pode ser uma sala de aula, um consultório médico, uma fábrica, uma casa) em que possam conviver e colaborar os incomuns. A floresta aparece, desse ponto de vista, não apenas como utopia, mas também como um pressuposto, mesmo que em determinado contexto ela não preexista. Contra o deserto da civilização, o sonho de uma escola floresta aparece como o sonho de uma imanência. Como se já estivéssemos na floresta: só assim poderemos estar nela.

Neste sentido, o coletivo pode se apresentar como uma arte da floresta. Um artifício do povo da floresta, que seja. A floresta é o artifício que suporta o incomum. Neste sentido, 
não estamos tão distantes da formulação de um antigo formalista russo, Victor Chklovsky, para quem a arte era um conjunto de procedimentos capaz de produzir estranheza, devolvendo assim uma sensação de vida às coisas. (CHKLOVSKY, 1976, p. 45) O povo da floresta é um povo estranho por vocação.

\title{
Notas
}

\begin{abstract}
1 As reflexões que constituem este artigo não seriam possíveis sem um aprendizado coletivo estabelecido nos espaços em que aconteceram os encontros da Oficina Experimental de Poesia (2011-2018). Foi com poetas e nãopoetas inte-ressados no fazer coletivo, tanto de mundo quanto de linguagem, que se gestou essa reflexão, que surge no ano se-guinte ao fim do coletivo, e meia década depois de encontros semanais onde pude aprender com centenas de pessoas. Convivem nestes pensamentos essas pessoas, e a elas agradeço imensamente.
\end{abstract}

2 Aqui formula-se um pensamento a propósito dessa concepção de cultura análogo ao que propôs Paulo Freire, quando propôs pensar a pedagogia da dominação como uma pedagogia "bancária". A esse propósito, cf. "A educação bancá-ria como instrumento da opressão. Seus pressupostos, sua crítica" em FREIRE, Paulo. Pedagogia do oprimido. São Paulo: Paz \& Terra, 2018, pp. 79-85.

30 ideal de um novo tribalismo é originalmente de Hermann von Keyserling, em 0 mundo que nasce, livro em que de-fende esse arquétipo - fruto da modernização de países não-europeus - como modelo de excelência da modernidade. 0 bárbaro tecnizado seria aquele capaz de ingressar no mundo da técnica moderna sem se misturar à densidade da tradição ocidental. Cf. KEYSERLING, Hermann de. Le monde qui nait. Trad. de Christian Sénéchal. Paris: Stock, 1932.

4 A ideia de inacabamento seguiria com Freire até o final de sua vida, como vemos na Pedagogia da autonomia. (1996, pp. 50-52)

Poiésis, Niterói, v. 20, n. 33, jan./jun. 2019. 


\section{Referências}

ALIGHIERI, Dante. A divina comédia - Inferno. Trad. Italo Eugenio Mauro. São Paulo: Editora 34, 2010.

ANDRADE, Oswald de. A utopia antropofágica. São Paulo: Globo, 2011.

ANDRADE, Oswald de. Obras completas. Vol. 7. Rio de Janeiro: Civilização brasileira, 1974.

ARENDT, Hannah. A condição humana. Trad. Roberto Raposo. Rio de Janeiro: Forense Universitária, 2014.

ARENDT, Hannah. Entre o passado e o futuro. Trad. Mauro W. Barbosa. São Paulo: Perspectiva, 2013.

ARISTÓTELES. Poética. Trad. Paulo Pinheiro. São Paulo: Editora 34, 2017.

BAUDELAIRE, Charles. Poesia e Prosa. Vol. único. Rio de Janeiro: Nova Aguilar, 1995.

BENJAMIN, Walter. Estética e sociologia da arte. Trad. João Barrento. Belo Horizonte: Autêntica, 2017.

BENJAMIN, Walter. O anjo da história. Trad. João Barrento. Belo Horizonte: Autêntica, 2012.

CHAUÍ, Marilena. Conformismo e resistência. Belo Horizonte; Rio de Janeiro: Autêntica; Editora Fundação Perseu Abramo, 2018.

CHKLOVSKY, Viktor. A arte como procedimento. In Teoria da Literatura: Formalistas Russos. $3^{a}$ ed. Porto Alegre: Editora Globo, 1976, pp. 39-56.

ELIADE, Mircea. História das crenças e das ideias religiosas, volume I: da Idade da Pedra aos mistérios de Elêusis. Trad. Roberto Cortes de Lacerda. Rio de Janeiro: Zahar, 2010. 
FREIRE, Paulo. Pedagogia da autonomia. Saberes necessários à prática educativa. São Paulo: Paz \& Terra, 1996.

FREIRE, Paulo. Pedagogia do oprimido. São Paulo: Paz \& Terra, 2018.

KEYSERLING, Hermann de. Le monde qui nait. Trad. de Christian Sénéchal. Paris, Stock, 1932.

KOSBY, Marília Floôr. Mugido. Rio de Janeiro: Garupa, 2017.

NETO, João Cabral de Melo. A escola das facas. In Poesia Completa 1940-1980. Lisboa: INCM, 1986.

POUND, Ezra. A arte da poesia. Ensaios de Ezra Pound. Trad. Heloysa de Lima Dantas e José Paulo Paes. São Paulo: Ed. Cultrix; EdUSP, 1976. 